\title{
Antimicrobial Effect of Buffered Sodium Citrate (BSC) on Foodbome Pathogens in Liquid Media and Ground Beef
}

\author{
Si Hyun Ryu ${ }^{1 \dagger}$ and Daniel Y. C. Fung ${ }^{2}$ \\ ${ }^{I}$ Department of Nutrition and Foodservice Management, Paichai University, Daejeon 302-735, Korea \\ ${ }^{2}$ Department of Animal Sciences and Industry, and Food Science Institute, \\ Kansas State University, Manhattan, Kansas 66506, USA
}

\begin{abstract}
The antimicrobial effects of a commercially available, buffered sodium citrate (BSC) were evaluated for the reduction of total aerobic bacteria count, Salmonella Typhimurium, Escherichia coli O157:H7, Listeria monocytogenes and Staphylococcus aureus in a liquid medium and ground beef. BSC at $0,1,2$ and $4.8 \%$ (wt/vol) or 0,3 , and $4.8 \%$ (wt/wt) was mixed into inoculated brain heart infusion (BHI) broth and ground beef (80\% lean), respectively. BSC at concentrations of 1 and $2 \%$ did not inhibit growth of the pathogens tested in BHI broth. $E$. coli $0157: \mathrm{H7}$ in BHI broth with $4.8 \%$ BSC was significantly reduced $(\mathrm{p}<0.05)$ by $3 \sim 4 \mathrm{log} \mathrm{CFU} / \mathrm{mL}$ compared with the control for up to 4 days. At $4.8 \%$, BSC treatment of ground beef most significantly reduced $(p<0.05)$ total aerobic count and $E$. coli $0157: H 7$ by 2.1 and $2.0 \mathrm{log} \mathrm{CFU} / \mathrm{g}$, respectively. This study indicates that the legally allowable level of $1.3 \%(w t / w t) ~ B S C$ is not effective for reducing the pathogens tested in ground beef stored at $7^{\circ} \mathrm{C}$.
\end{abstract}

Key words: antimicrobial, buffered sodium citrate, pathogens, ground beef, BHI broth

\section{INTRODUCTION}

In spite of developments in the food industry and hygiene technology, outbreaks of illness resulting from foodborne pathogens is still one of the most important issues in the world food market. To improve the safety of foods, studies have been performed evaluating the use of various antimicrobial agents, which can inhibit foodborne pathogens in foods.

The United States Department of Agriculture-Food Safety and Inspection Service (USDA-FSIS) has evaluated and approved the use of buffered sodium citrate (BSC) as a safe and suitable food ingredient in meat, poultry and egg products. BSC is sodium citrate that has been buffered to a $\mathrm{pH}$ of 5.6 with citric acid. Currently, $1.3 \%$ is the maximum allowable level of BSC in meat, poultry and egg products as an antimicrobial agent (1).

Some of the most promising studies have shown BSC to be an effective microbial inhibitor of foodborne pathogens such as Listeria and Clostridium. The use of BSC for vacuum packaged frankfurters was reported to be able to prevent the outgrowth of Listeria monocytogenes for over 4 weeks of storage at $4^{\circ} \mathrm{C}(2)$. However, the addition of $1 \% \mathrm{BSC}$ did not inhibit growth of L. monocytogenes in cooked ham product stored at $4^{\circ} \mathrm{C}$ (3). A BSC concentration of $\geq 1.0 \%$ was required to reduce
Clostridium perfringens during chilling of roast beef and injected pork (4), whereas in cooked vacuum-packaged restructured roast beef with sodium citrate buffered to $\mathrm{pH} 5.6$ at a concentration of $\geq 2 \%$ (wt/wt) sufficiently inhibited $C$. perfringens growth over an $18 \mathrm{hr}$ cooling period (5).

As can be seen by previously reported research, there are conflicting results on the effectiveness of different levels of BSC. Also, there are limited published studies on the inhibitory effects of BSC. Therefore, the purpose of this study was to evaluate the effect of different concentrations of commercially available BSC ( $\mathrm{IONAL}^{\mathrm{TM}}$ ) as a microbial inhibitor of total aerobic count, $S$. Typhimurium, E. coli O157:H7, L. monocytogenes, and Staphylococcus aureus in brain heart infusion (BHI) broth and in ground beef. Raw ground beef was chosen since it provides a challenging matrix of natural microflora, protein, and fat. Furthermore, if effective, the addition of BSC might increase the shelf life of raw ground beef, thereby saving the meat industry money while improving the food safety for consumers. Since the addition of up to $1.3 \%$ of BSC (wt/wt) is legally allowed, the purpose of this research was to ascertain whether or not the allowable level of BSC is able to inhibit or reduce the growth of a range of common foodborne pathogens. Since the effective level of BSC is in conflict, higher 
than allowable levels were also used to determine the actual antimicrobial effectiveness of BSC.

\section{MATERIALS AND METHODS}

\section{Preparation of culture}

S. Typhimurium (ATCC 14028), E. coli O157:H7 (ATCC 43889), L. monocytogenes (ATCC 49594) and S. aureus (ATCC 25923) obtained from the Food Microbiology Laboratory at Kansas State University were used in this study. The cultures were tested for purity using Gram reactions and biochemical tests: API 20E kits (bioMerieux, Inc., Hazelwood, MO, USA) for Gramnegative bacteria and BBL Crystal kits (Becton Dickinson, Sparks, MD, USA) for Gram-positive bacteria. The strains were grown individually in $\mathrm{BHI}$ broth at $35^{\circ} \mathrm{C}$ for $24 \mathrm{hr}$. After incubation, $1 \mathrm{~mL}$ of each culture broth was transferred to sterilized $500 \mathrm{~mL}$ polycarbonate centrifuge bottles (Nalgene, Rochester, NY, USA) containing 100 $\mathrm{mL}$ of BHI broth and incubated at $35^{\circ} \mathrm{C}$ for $24 \mathrm{hr}$. The cultures were then centrifuged (Model JA-14, International Equipment Co., Needhan Heights, MA, USA) at $12,000 \times \mathrm{g}$ for $10 \mathrm{~min}$ at $4^{\circ} \mathrm{C}$, the supernatant was removed and the pellet was resuspended with $100 \mathrm{~mL}$ of $0.1 \%$ sterile peptone water. Equal aliquots of $2.5 \mathrm{~mL}$ of each resuspended culture were transferred into sterilized test tubes to make pathogen cocktails. The cocktails were mixed by vortex (Touch Mixer, Model 231, Fisher Scientific Lid., Ontario, Canada) and then serially diluted to approximately $6 \log \mathrm{CFU} / \mathrm{mL}$ with $0.1 \%$ sterile peptone water.

\section{Preparation of liquid medium with BSC}

The commercially available BSC, known as IONAL ${ }^{\mathrm{TM}}$ (pH 5.6) was purchased from World Technology Ingredients Company (Kingston, NY, USA). The BSC was added at $0,1,2$, and $4.8 \mathrm{~g}$ into sterile bottles containing 100, 99, 98 and $95.2 \mathrm{~mL}$ of sterilized BHI broth, respectively. These $100 \mathrm{~mL}$ mixtures were then homogenized for 1 min using a vortex to result in liquid medium samples with $0,1,2$, and $4.8 \%(\mathrm{wt} / \mathrm{vol}) \mathrm{BSC}$. The prepared pathogen cocktail was inoculated at $1 \mathrm{~mL}$ into each liquid medium $(100 \mathrm{~mL})$ and thoroughly mixed to make inocula of approximately $4 \log \mathrm{CFU} / \mathrm{mL}$. BHI sample without added BSC was considered a control. After incubation, the liquid media samples were stored at 0 , 1,2 , and 4 days at $35^{\circ} \mathrm{C}$ for microbiological analysis.

\section{Preparation of ground beef with BSC}

Ground beef ( $20 \%$ fat) was purchased from a local grocery in Manhattan, KS. The $\mathrm{pH}$ of the ground beef purchased was 5.58. BSC was shown to be ineffective for reduction or inhibition of all natural and inoculated organisms at $\leq 2 \%$ when used in BHI broth. Therefore, 3 and $4.8 \%$ (wt $/ \mathrm{wt}$ ) levels of BSC were used to determine the antimicrobial effect in ground beef. The BSC at 6 and $9.6 \mathrm{~g}$ were added to 194 and $190.4 \mathrm{~g}$ of ground beef, respectively, and aseptically mixed, resulting in 3 and $4.8 \%$ BSC treatments. The prepared cocktail was inoculated into the ground beef at $1 \%(\mathrm{vol} / \mathrm{wt})$ and mixed evenly for $5 \mathrm{~min}$ by gloved hands to make ground beef samples with approximately $4 \log \mathrm{CFU} / \mathrm{g}$ of inocula. The inoculated ground beef without added BSC was considered a control. The ground beef mixed with pathogens and 0,3 , and $4.8 \%$ BSC was dispensed individually into $25 \mathrm{~g}$ portions and placed in sterile stomacher bags (Model SFB-410, Spiral Biotech. Inc., Bethesda, MD, USA). The samples were stored at $0,1,3$, and 5 days at $7^{\circ} \mathrm{C}$ for microbiological analysis.

\section{Microbiological analysis}

For each sampling time, BHI with 0, 1, 2 and 4.8\% BSC and inoculated pathogen were serially diluted in $0.1 \%$ sterile peptone water. The ground beef samples with 0,3 and $4.8 \%$ BSC inoculated with pathogens were homogenized with $225 \mathrm{~mL}$ of $0.1 \%$ peptone water using a stomacher (Lab Blender 400, A. J. Seward Medical, London, UK) for $2 \mathrm{~min}$ and then were serially diluted in $0.1 \%$ peptone water. The diluted samples were spiral plated onto duplicate Tryptic Soy Agar (TSA, Difco, Detroit, USA) for total aerobic count, Xylose Lysine Desoxycholate Agar (XLD, Difco) for $S$. Typhimurium count, MacConkey Sorbitol Agar (MSA, Difco) for $E$. coli O157:H7 count, Modified Oxford Agar (MOX, Difco) for L. monocytogenes count and Baird Parker Agar (BP, Difco) for S. aureus count using a Spiral plater (Autoplate 4000, Spiral Biotech. Inc., Bethesda, MD, USA). After spiral plating, the petri dishes were incubated at $35^{\circ} \mathrm{C}$ for $24 \mathrm{hr}$ before viable cells were manually counted and recorded (American Optical Co., NY, USA).

\section{Statistical analysis}

All cell counts were converted to log scale for statistical analysis. A total of 21 samples underwent statistical analysis of the microbial data using the GLM (General Linear Model) procedure of SAS (SAS Institute, Cary, NC, USA). All experimental data were treated as a Randomized Complete Block (RCB) design with repeated measurements. Mean values among treatments at each storage day were analyzed using Fisher's least significant difference (LSD) method to compare the effects of the different concentration of BSC treatments on pathogen growth. The level of significance among means values was determined at the $95 \%$ confidence limit. This experiment was repeated in its entirety three 

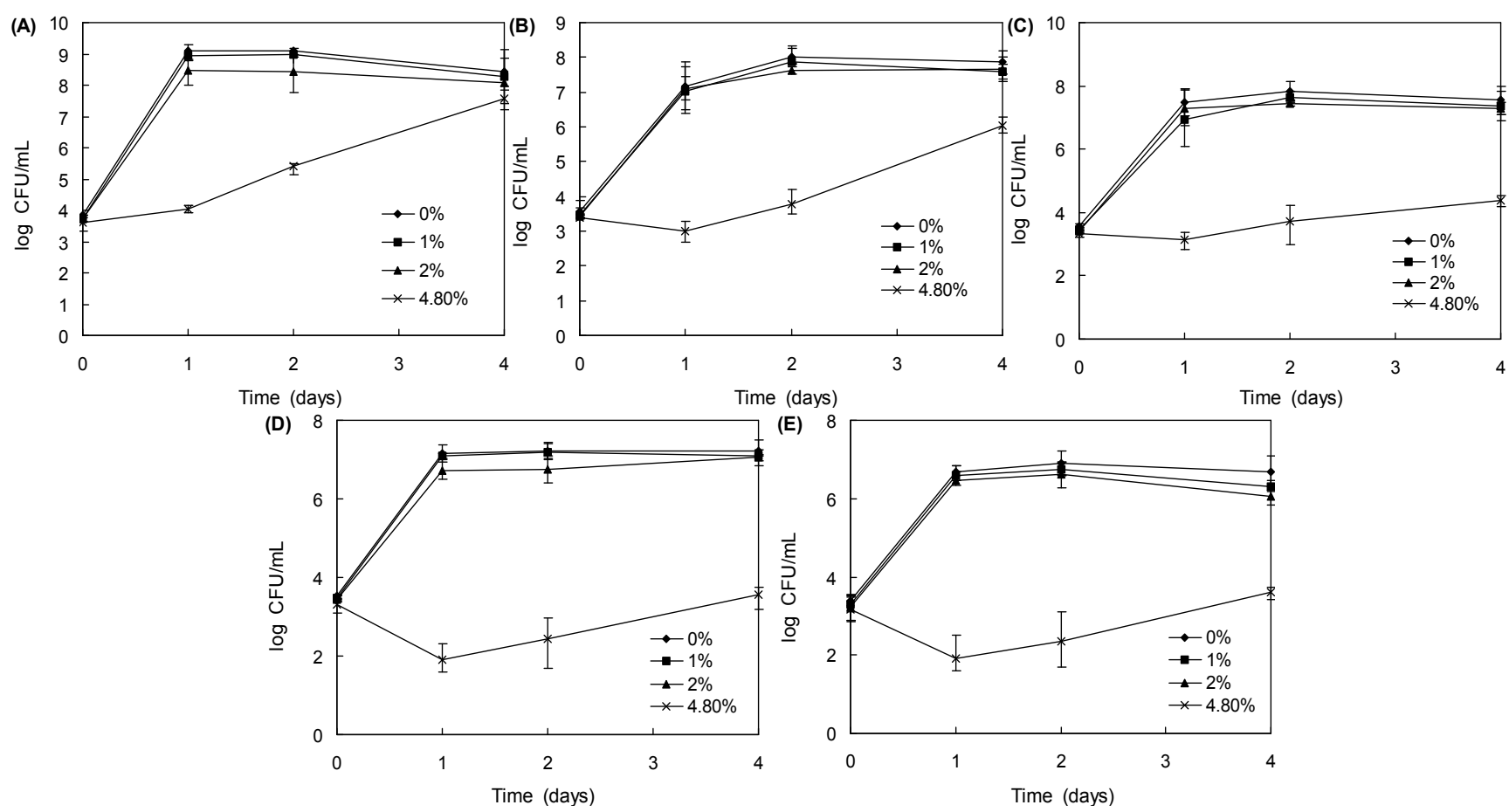

Fig. 1. Growths of total aerobic bacteria (A), Salmonella Typhimurium (B), Escherichia coli O157:H7 (C), Listeria monocytogenes (D), Staphylococcus aureus (E) in BHI broth with $0,1,2$ and $4.8 \%$ BSC at $35^{\circ} \mathrm{C}$ for 4 days. Each value is expressed as mean $\pm \mathrm{SD}, \mathrm{n}=3$.

times.

\section{RESULTS AND DISCUSSION}

\section{Antimicrobial effect of BSC against foodbome pa- thogens in BHI medium}

The results of BSC treatment applications for microbial reduction in BHI broth at $35^{\circ} \mathrm{C}$ showed the greatest inhibition of inoculated pathogens using 4.8\% (Fig. 1). Total aerobic count grew from approximately $4 \log$ CFU/ $\mathrm{mL}$ to $8 \sim 9 \log \mathrm{CFU} / \mathrm{mL}$ in the control and in 1 and $2 \%$ BSC treated samples after 1 day but was significantly suppressed $(\mathrm{p}<0.05)$ by 5.1 and $3.7 \log \mathrm{CFU} / \mathrm{mL}$ in BHI broth with $4.8 \%$ BSC compared with the control on days 1 and 2, respectively (Fig. 1A). By day 4, in 4.8\% BSC the number increased to approximately the level of the control, 1, and $2 \%$ BSC treatment. In the control, 1, and $2 \%$ BSC, the inoculated $S$. Typhimurium grew approximately to $7 \log \mathrm{CFU} / \mathrm{mL}$ after 1 day and then only slight population differences were observed but no significant difference from controls after 4 days were observed (Fig. 1B). At $4.8 \%$ BSC, $S$. Typhimurium was gradually and significantly suppressed $(\mathrm{p}<0.05)$ for 2 days and then increased to approximately $6.0 \log \mathrm{CFU} / \mathrm{mL}$ on day 4 , which was still significantly lower than the control, 1, and 2\% BSC treatment data. E. coli $\mathrm{O} 157: \mathrm{H} 7$ was significantly suppressed $(\mathrm{p}<0.05)$ by $3 \sim 4 \log \mathrm{CFU} / \mathrm{mL}$ compared with the control for up to 4 days in $4.8 \%$ BSC
(Fig. 1C). L. monocytogenes and S. aureus showed low counts overall and slightly increased from approximately $1.9 \log \mathrm{CFU} / \mathrm{mL}$ on day 1 to only $3.6 \log \mathrm{CFU} / \mathrm{mL}$ on day 4 in the presence of $4.8 \%$ BSC (Fig. 1D, E).

These data shows that BSC can be used to control the growth of Gram-negative and Gram-positive bacteria. When used at a level of $4.8 \%$, the BSC treatments in BHI broth reduced $(\mathrm{p}<0.05)$ total aerobic count, $S$. Typhimurium, E. coli $\mathrm{O} 157: \mathrm{H} 7$, L. monocytogenes and $S$. aureus by $0.7,1.9,3.2,3.6$ and $3.1 \log \mathrm{CFU} / \mathrm{mL}$, respectively, compared with the control on day 4 , whereas 1 and $2 \%$ treatments were not sufficient to suppress any of the test pathogens. These results indicate that BSC at concentrations of $>2 \%$ is required to reduce all test pathogens in $\mathrm{BHI}$ broth for 4 days at $35^{\circ} \mathrm{C}$.

\section{Antimicrobial effect of BSC against foodbome pa- thogens in ground beef}

Similar to the broth experiment, the results of BSC treatment applications on microorganisms in ground beef at $7^{\circ} \mathrm{C}$ showed greater inhibition of inoculated pathogens with higher concentrations of BSC treatments (Fig. 2). Total aerobic count reached $6.2 \log \mathrm{CFU} / \mathrm{g}$ in the control samples on day 3 and remained constant through 5 days. With the 3\% BSC application, total aerobic count slightly increased for 3 days but was reduced to initial inoculum levels on day 5. The addition of $4.8 \%$ BSC inhibited the growth of total aerobic count until 5 days 

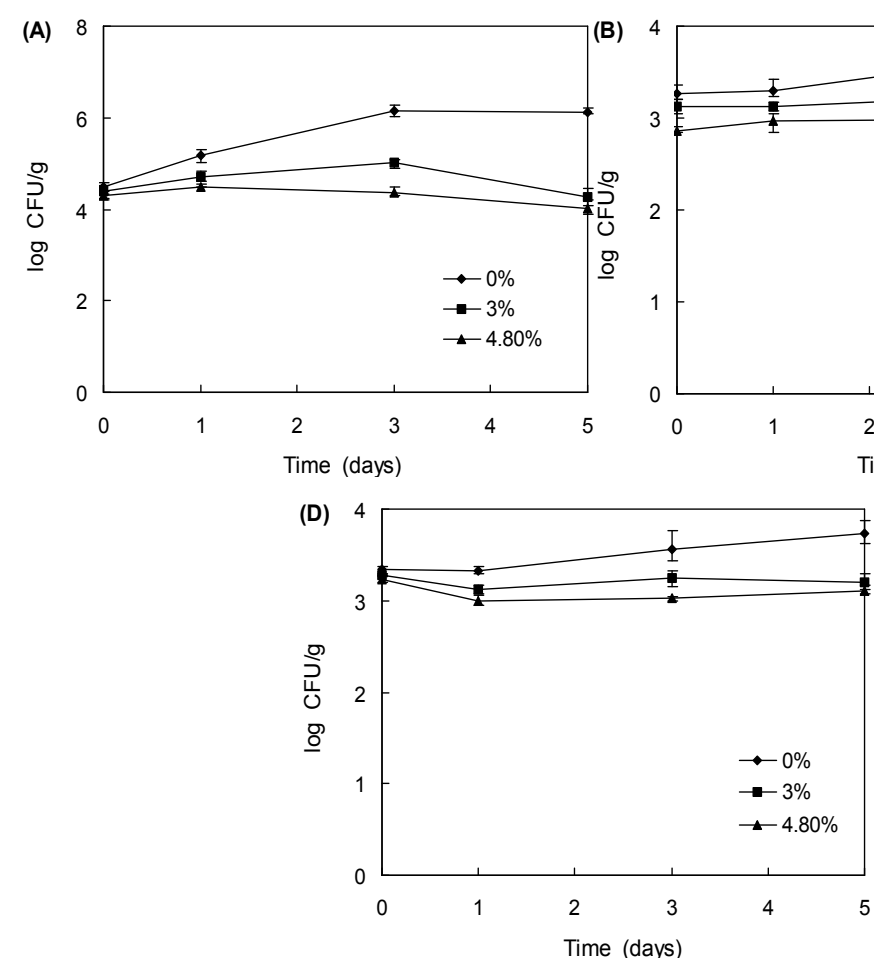
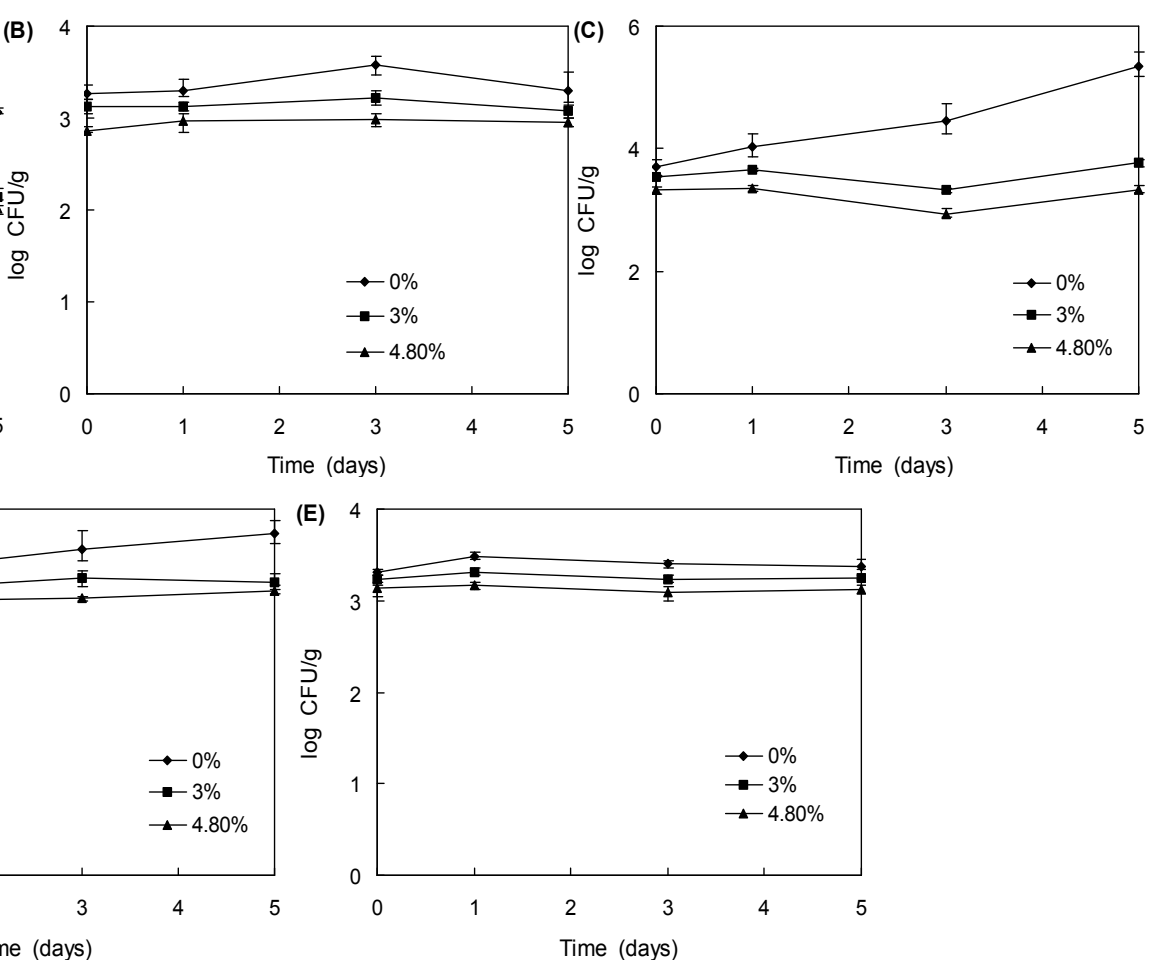

Fig. 2. Growths of total aerobic bacteria (A), Salmonella Typhimurium (B), Escherichia coli O157:H7 (C), Listeria monocytogenes (D), Staphylococcus aureus (E) in ground beef with 0,3 and $4.8 \% \mathrm{BSC}$ at $7^{\circ} \mathrm{C}$ for 5 days. Each value is expressed as mean $\pm \mathrm{SD}$, $\mathrm{n}=3$.

of storage (Fig. 2A). These findings are in accordance with other studies; Ceylan and Marsden (6) reported that the use of $1 \%$ BSC treatment was ineffective for reducing or inhibiting the total aerobic count in ground beef stored for 5 days at $4^{\circ} \mathrm{C}$. In fact, after 5 days of storage, the counts in the control and ground beef with $1 \%$ BSC increased and reached $7.0 \mathrm{log}$ CFU/g. Trater (7) also showed that $1 \%$ BSC treatment had no effect on aerobic plate count in cured and uncured beef frankfurters held at $10^{\circ} \mathrm{C}$ for 2 weeks.

In the pathogen study, $S$. Typhimurium maintained the level of approximately $3.0 \mathrm{log} \mathrm{CFU} / \mathrm{g}$ for 5 days with $4.8 \%$ BSC (Fig. 2B). E. coli O157:H7 grew to $5.3 \mathrm{log}$ $\mathrm{CFU} / \mathrm{g}$ in controls by day 5 , but was significantly suppressed $(\mathrm{p}<0.05)$ by 1.5 and $2.0 \log \mathrm{CFU} / \mathrm{g}$, respectively, in 3 and $4.8 \%$ BSC after 5 days (Fig. 2C). S. aureus and $L$. monocytogenes were detected at low levels of $3.1 \sim 3.5$ and $3.0 \sim 3.5 \log \mathrm{CFU} / \mathrm{g}$, respectively, on every treatment through the entire incubation period (Fig. 2D, E). L. monocytogenes was also significantly lower $(\mathrm{p}<$ 0.05 ) by $0.5 \sim 0.6 \log \mathrm{CFU} / \mathrm{g}$ compared with the control at level of 3 and $4.8 \%$ BSC.

The $4.8 \%$ BSC treatment of ground beef was necessary to significantly reduce $(\mathrm{p}<0.05)$ total aerobic count, $S$. Typhimurium, E. coli $\mathrm{O} 157: \mathrm{H} 7$, L. monocytogenes and $S$. aureus by $2.1,0.3,2.0,0.6$ and $0.3 \log \mathrm{CFU} / \mathrm{g}$, respectively, compared with control on day 5. Popula- tions of E. coli $\mathrm{O} 157: \mathrm{H} 7$ was reduced to the greatest extent on day 5 by $4.8 \%$ BSC in ground beef. The results of this study indicate that the $4.8 \%$ BSC in ground beef was most effective for controlling E. coli $\mathrm{O} 157: \mathrm{H} 7$ compared to the other pathogens tested.

The antimicrobial effect of BSC was greater in BHI broth than in ground beef. This may be due to the ability of proteins and fats in ground beef to protect bacterial cells and bind antimicrobial agents. BSC also may not be homogenously mixed into a relatively solid matrix; and may be less soluble at the meat $\mathrm{pH}$. To further complicate these issues, many bacteria are naturally present in ground meat; and the high numbers of cells may protect bacteria from contact with BSC.

BSC is sodium citrate buffered with citric acid and is approved for use as a direct food additive (8). Sodium citrate has been reported to act as an antimicrobial agent (9-12) due to its chelation properties and cytoplasmic $\mathrm{pH}$ depression (13). Ayres et al. (14) also suggested that sodium citrate chelates divalent metal ions, thereby creating holes on the Gram-negative bacterial cell wall which lead to leakage and eventually lysis of the cell. It is possible that the BSC in ground beef may act as a chelator of cations essential for microbial growth and enhance emulsification and water holding capacity. Tying up cations in the muscle also inhibits oxidative rancidity and slows the rate of color fading of meat. However, 
$1 \%$ BSC treatment allowed more cured color fading than the control treatment (7).

The results obtained from this study indicate that the use of $4.8 \%$ BSC had antibacterial effects against both Gram-negative and Gram-positive foodborne pathogens in both a liquid medium and ground beef. The amount of BSC necessary to perform these actions effectively is much greater than $1.3 \%$ when used in a ground beef matrix. Other researchers found that the combination of BSC and other organic acids provided synergistic antimicrobial activity $(6,15,16)$.

The USDA-FSIS is currently permitting BSC at a level up to $1.3 \%$ to inhibit the growth of pathogens in meat and poultry products (1). However, in this study BSC treatments of $\leq 2 \%$ were insufficient to suppress any of the tested pathogens in liquid medium. All of the tested pathogens were most effectively inhibited by $4.8 \%$ BSC, which is not presently allowed. Thus, these results contribute additional information for the use of commercially available BSC in meat products for purposes of inhibiting the growth of pathogens. Additional research should be undertaken to determine the antimicrobial effects of BSC in different meat products.

\section{ACKNOWLEDGEMENTS}

This material is based upon work supported by the Cooperative State Research Education, and Extension Service, the United States Department of Agriculture, under agreement No. 93-34211-8362. This paper is contribution No. 04-415-J from the Kansas Agricultural Experiment Station, Manhattan, KS 66506-4008.

\section{REFERENCES}

1. United States Department of Agriculture, Food Safety and Inspection Service. 2010. Safe and suitable ingredients used in the production of meat, poultry, and egg products. FSIS directive 7120.1 Amendment 1. Revision 3. Washington, DC, USA. $\mathrm{p} 8$.

2. Marsden JL, Phebus RK, Thippareddi H. 2001. Listeria risks in ready-to-eat meats can be controlled using a true HACCP approach. USDA Scientific Conference. Washington DC, USA. p 6.

3. Stekelenburg FK, Kant-Muermans MLT. 2001. Effects of sodium lactate and other additives in a cooked ham product on sensory quality and development of a strain of Lactobacillus curvatus and Listeria monocytogenes. Int $J$ Food Microbiol 66: 197-203.

4. Thippareddi H, Juneja VK, Phebus RK, Marsden JL,
Kastner CL. 2003. Control of Clostridium perfringens germination and outgrowth by buffered sodium citrate during chilling of roast beef and injected pork. J Food Prot 66: 376-381.

5. Sabah JR, Thippareddi JL, Marsden JL, Fung DYC. 2003. Use of organic acids for the control of Clostridium perfringens in cooked vacuum-packaged restructured roast beef during an alternative cooling procedure. J Food Prot 66: $1408-1412$

6. Ceylan E, Marsden JL. 2002. Antimicrobial effect of buffered sodium citrate, and combination of buffered sodium citrate and sodium diacetate on total aerobic count of ground beef stored at $4^{\circ} \mathrm{C}$. The Food Safety Consortium Annual Meeting. Manhattan, KS, USA.

7. Trater CM. 2004. Applications of sodium lactate and buffered sodium citrate in cured and uncured all beef frankfurters: effects on microbial, instrumental color and subjective color shelf-life. MS thesis. Kansas State University, Manhattan, KS, USA.

8. United States Department of Agriculture, Food Safety and Inspection Service. 2010. Guidance on ingredients and sources of radiation used to reduce microorganisms on carcasses, ground beef, and beef trimmings. Available at: http://www.fsis.usda.gov/Frame/FrameRedirect.asp?main= http://www.fsis.usda.gov/OPPDE/rdad/FRPubs/00-022N/I ngredGuid.htm

9. Maca JV, Miller RK, Acuff GR. 1997. Microbiological sensory and chemical characteristics of vacuum-packages ground beef patties treated with salts of organic acids. $J$ Food Sci 62: 591-596.

10. Blaszyk M, Holley RA. 1998. Interaction of monolaurin, eugenol and sodium citrate on growth of common meat spoilage and pathogenic organisms. Int J Food Microbiol 39: $175-183$

11. Scannell AGM, Hill C, Buckley DJ, Arendt EK. 1997. Determination of the influence of organic acids and nisin on shelf-life and microbiological safety aspects of fresh pork sausage. J Appl Microbiol 83: 407-412.

12. Scannell AGM, Ross RP, Hill C, Arendt EK. 2000. An effective lacticin biopresevative in fresh pork sausage. $J$ Food Prot 63: 370-375.

13. Stratford M. 1999. Traditional preservatives-organic acids. In Encyclopedia of Food Microbiology. Robinson RK, Batt CA, Patel PD, eds. Academic, New York, USA. p 17291737.

14. Ayres HM, Furr JR, Ruseel AD. 1999. Effect of divalent cations on permeabilizer-induced lysozyme lysis of Pseudomonas aeruginosa. Lett Appl Microbiol 27: 372-374.

15. Ceylan E, Hajmeer MN, Marsden JL. 2002. Validation study of the efficacy of buffered sodium citrate, and combination of buffered sodium citrate and sodium diacetate against Listeria monocytogenes on beef franks. The Food Safety Consortium Annual Meeting. Manhattan, KS, USA.

16. Juneja VK, Thippareddi H. 2004. Inhibitory effects of organic acid salts on growth of Clostridium perfringens from spore inocula during chilling of marinated ground turkey breast. Int J Food Microbiol 93: 155-163.

(Received August 10, 2010; Accepted September 11, 2010) 